Original Article

\title{
A PILOT TRAIL: EFFECTIVENESS OF BIBLIOTHERAPY ON QUALITY OF LIFE, PSYCHOLOGICAL DISTRESS AND DEPRESSION AM ONG PATIENT WITH CHRONIC LEG AND FOOT ULCER IN MANGALORE
}

\author{
Kirupa $\mathbf{P}^{1}$, Preetham Rai $\mathbf{B}^{2} \&$ Srinivasa Bhat $\mathbf{U}^{3}$ \\ ${ }^{1}$ Research Scholar, Nitte University, ${ }^{2}$ Professor, Department of Surgery, ${ }^{3}$ Associate Professor, \\ Department of Psychiatry, K.S. Hegde Medical Academy, \\ Nitte University, Mangalore, Karnataka, India. \\ Correspondence : \\ Kirupa $\mathbf{P}$ \\ Research Scholar, Nitte University, M angalore - 575018. \\ Mobile : +919844958743 E-mail : parthasarathikirupa@gmail.com
}

\section{Abstract:}

Introduction : Many clients living with chronic leg and foot ulcers experience diminished quality of life, pain, psychosocial maladjustment, limited work capacity, and physical disabilities. Bibliotherapy helps the individual to cope up with illness.

Objectives: Assess the pretest level of psychological distress, quality of life and depression in both Interventional and control group. Evaluate the effectiveness of bibliotherapy on quality of life, psychological distress and depression

Methods : Pilot study was conducted among the twenty patients with chronic leg and foot ulcer .Randomized clinical trial comparison with pair group method was used to evaluate the effectiveness of bibliotherapy .Data were assessed by using chronic wound impact schedule, Kessler's psychological distress scale and beck depression inventory were used to assess the quality of life, psychological distress and depression respectively. Simple random sampling by lottery method was used to collect the data.

Results: Findings show that there is mean of the quality of life (56.3), distress (28.3) and depression (22.5) were falls on the moderate level among the patient suffering with chronic leg and foot ulcer. Two way analysis of variance proves that bibliotherapy highly significant in increasing quality of life $(F=20.3, P \varangle 0.001)$, decreasing the psychological distress ( $F=25.2, P \varangle 0.01)$ and decreasing depression ( $F=5.18, P<0.05)$.

Conclusion. Need based bibliotherapy is effective to meet the psychological aspects of chronic legand foot ulcer

Key words: leg and foot ulcer, bibliotherapy, distress, quality of life, Depression

\section{Introduction}

Epidemiology and economic burden of the chronic wound was serious endemic in the developed and developing countries in the world.

A recent study in the UK shows that a prevalence of patients with a chronic wound was 3.55 per 1000 population. In the chronic wounds, leg and foot ulcer accounts for the $28 \%$ Access this article online Quick Response Code

四年品
wounds. Prevalence of chronic wounds among hospital inpatients was $30.7 \%{ }^{1}$. In India it is estimated a prevalence rate of chronic wounds at 4.5 per 1000 population.
The etiology of chronic wounds varies from diabetes, atherosclerosis, tuberculosis, leprosy, venous ulcers, pressure ulcers, vasculitis and trauma ${ }^{2}$.

In Bangalore Victoria Hospital a clinical study of the ulcer of leg among 200 clients reported that diabetic ulcer accounting for 68 cases (34\%) followed by venous ulcer $(24 \%)$, traumatic ulcer $(16 \%)$, arterial ulcer $(12 \%)$ malignant ulcer (5\%), tropic ulcer (3\%) and others 12 $(6 \%)$.Ulcers are breaks in the layers of the skin that fail to heal. They may be accompanied by inflammation ${ }^{3}$.

Chronic leg and foot ulcers are often painful and recurrent, and they can have a negative Physical, physiological, social and psychological impact on clients and families, thus decreasing their quality of life. Leg and foot ulcers are often recalcitrant to healing, tend to recur, and become long- 
term chronic healthcare problems ${ }^{4}$. Research reported that chronic physical illness one of the increased risk of depression ${ }^{5}$.

Many clients living with chronic leg and foot ulcers experience diminished quality of life, pain, psychosocial maladjustment, limited work capacity, and physical disabilities ${ }^{4}$.

\section{Need for the Study}

In India, L H Hiranandani Hospital, world mental health day celebration 2011 reported that patients suffering from a physical illness, especially chronic, tend to develop not just minor mental problems like distress and anxiety, but also major ones like depression, phobias and even sexual dysfunction. About $14-20 \%$ of chronically ill patients have psychological problems, apart from minor distress and anxiety ${ }^{5}$.

Pain and stress may slow wound healing through various intricate mechanisms. Psychological stressor that triggers the hypothalamic-pituitary-adrenal axis promoting the production of vasopressin and glucocorticoid (cortisol). Cortisol reduces the immune- inflammatory response, suppresses cellular differentiation and proliferation, and inhibits the regeneration of endothelial cells and delays collagen synthesis ${ }^{6}$.

The psychological impact of chronic physical illness can be prevented by bibliotherapy. Bibliotherapy as defined by the American Library Association is the use of selected reading materials as therapeutic adjuncts in medicine and psychiatry; also, guidance in the solution of personal problemsthrough directed reading ${ }^{7}$.

Bibliotherapeutic intervention may be undertaken for many reasons such as to develop an individual's selfconcept; to increase an individual's understanding of human behavior or motivations to foster an individual's honest self-appraisal; to provide a way for a person to find interests outside of self; to relieve emotional or mental pressure; to show an individual that he or she is not the first or only person to encounter such a problem; to show an individual that there is more than one solution to a problem and to help an individual plan a constructive course of action to solve a problem ${ }^{8}$.

In Trinity College, Ireland the study was conducted on bibliotherapy is a form of self-administered treatment in which structured materials provide a means to alleviate distress. Thematic analyses revealed that bibliotherapy schemes are effective in alleviating the distress ${ }^{9}$.

In Indian Scenario need to focus the psychological perspective of patient with chronic leg and foot ulcer. The above literature indicated the therapeutic effect of bibliotherapy on the psychological distress and depression . Researcher interested to know the novel effect of bibliotherapy on psychological distress, quality of life and depression among the patients suffering with chronic leg and foot Ulcer.

\section{Objectives:}

1. Assess the pre test level of psychological distress, quality of life and depression in both Interventional and control group

2. Evaluate the effectiveness of bibliotherapy on quality of life, psychological distress and depression.

\section{Materials and Methods}

This study is the pilot trail for the main study to evaluate the effectiveness of bibliotherapy on selected psychological variables such as quality of life, distress and depression.

This randomized clinical trial was conducted between March 2013 to June 2013. In the evaluative approach, randomized control trial comparison with parallel group was chosen for this pilot trial. In this trail interventional group were received usual care along with bibliotherapy and control group were received only usual care. Pretest and baseline admission was done $1^{\text {st }}$ day ,Post test was administered on $7^{\text {th }}$ day , I follow up on $14^{\text {th }}$ day and II follow up was conducted on $21^{\text {st }}$ day for both interventional and control group.

\section{Sample \& sample size}

Patients those who are fulfilling the sampling criteria. 
Sample size comprises of 20 patients with chronic leg and footulcer.

Patients suffering with chronic leg and foot ulcer were randomized into interventional and control group by simple random sampling by lottery method.

\section{Setting}

The study was conducted in K.S Hegde medical college hospital, M angalore.

\section{Drawinga protocol}

Bibliotherapy is a use of books in therapeutic context by the researcher based on the Problem solving technique, Coping with the condition, therapeutic regimen and follow up in the form of storytelling, activity exercise, protocol and poetry presentation specific to the chronic leg and foot ulcer caused by the venousulcer and diabetic foot.

Researcher was started to prepare the intervention after the consultation with the experts and guides .Researcher was conducted a small qualitative study on experiences of patient living with chronic leg and foot ulcer in order to understand need of the person. Based on the findings and after collection of adequate literature the researcher was prepared book for patient suffering with chronic leg and foot ulcer.

This book is a contemporary approach to help the patient deal the problem both mentally and physically. Core concept of the book implies that accepting the illness, create knowledge and motivation of self care, caution about the complication, managing of day to day battle with chronic legwounds.

Content validity of the book obtained from the experts in the psychiatric, surgical and nursing field .After the validation, the book was translated in both Kannada and $M$ alayalam version. Book was prepared on $8^{\text {th }}$ grade level of reading.

\section{Sampling criteria}

Inclusion criteria : Patient those who are
2. Age between 30years-65years

3. Able to understand and speak either Kannada, $M$ alayalam or English

4. Both male and female.

5. Had the site of ulcer below knee.

6. Visited the K.SHegde hospital for the treatment.

7. In all the stages of diabetic foot ulcer or venous ulcer.

8. Underwent all the type of surgical procedure for the diabetic foot and venousulcer.

9. Patient in the stage of before and after the surgical procedure.

10.Educated above $10^{\text {th }}$ standard.

\section{Exclusion criteria}

1. Chronic leg and foot ulcer patient suffering with any other serious co existing illness.

2. Patient those who are uncooperative.

3. Patient those who are unconscious, drowsy and disoriented at the time of study.

4. Diagnosed with chronic alcoholism and alcohol dependant syndrome.

\section{Data collection procedure}

Data were collected from the participant by using sociodemographic proforma; Chronic wound impact schedule, Kessler's psychological distress scale and Beck depression inventory. The researcher recruited the participant based on the predetermined sampling criteria. Three instruments were translated into Kannada and Malayalam version and language validation done. Reliability of the three instruments was fall on above 0.7 by split half method and found to be reliable in the translated version of Kannada and M alayalam. Pre test was conducted to before the administration of the intervention Bibliotherapy was administered for one week in the intervention along with usual care

\section{Scientific adequacy of the research}

The study strictly followed the privacy, confidentiality of the ethical clearance procedure. This study conducted by the researcher as a part of $\mathrm{PhD}$ program.

1. Diagnosed as diabetic foot ulcer or venous ulcer. 


\section{Tables with caption separately}

Table 1-Independent test analysis between the interventional and control group

\begin{tabular}{|l|c|c|c|c|c|c|}
\hline Baseline data & \multicolumn{2}{|c|}{$\begin{array}{c}\text { Interventional } \\
\text { Group(10) }\end{array}$} & \multicolumn{2}{c|}{$\begin{array}{c}\text { Control } \\
\text { Group(10) }\end{array}$} & $\begin{array}{c}\mathbf{N}=\mathbf{2 0} \\
\text { Inference }\end{array}$ \\
\hline & Mean & SD & Mean & SD & Tvalue & \\
\hline Quality of life & 56.2 & 56.3 & 6 & 7.7 & $0.15, p>0.05$ & NS \\
\hline Psychological Distress & 28.3 & 6.3 & 27.1 & 3 & $0.5, p>0.05$ & NS \\
\hline Depression & 22.5 & 7.2 & 22 & 4.5 & $0.18, P>0.05$ & NS \\
\hline
\end{tabular}

$S, S^{*}, S^{* *}$ - significant $(P<0.05,0.01,0.001)$ NS- Non Significant $d f=18$

Table 2 : shows Mean, SD, M ean difference on quality of life among the Interventional and control group $\mathrm{N}=20$

\begin{tabular}{|l|c|c|c|c|c|}
\hline \multirow{2}{*}{$\begin{array}{l}\text { Data colle- } \\
\text { ction Point }\end{array}$} & \multicolumn{2}{|c|}{ Interventional } & \multicolumn{2}{|c|}{ Control } & Mean \\
\cline { 2 - 6 } & M ean & SD & Mean & SD & Difference \\
\hline Post test & 65.21 & 9.3 & 53.06 & 5.8 & 12.15 \\
\hline I follow Up & 67.8 & 9.18 & 54.64 & 5.3 & 13.2 \\
\hline II Follow Up & 70.74 & 7.8 & 52.24 & 5.4 & 18.5 \\
\hline
\end{tabular}

Table 3 : shows the Mean, SD and mean difference on the psychological distress in the Interventional and control group patients. $\mathrm{N}=20$

\begin{tabular}{|l|c|c|c|c|c|}
\hline \multirow{2}{*}{$\begin{array}{l}\text { Data colle- } \\
\text { ction Point }\end{array}$} & \multicolumn{2}{|c|}{ Interventional } & \multicolumn{2}{c|}{ Control } & Mean \\
\cline { 2 - 6 } & Mean & SD & M ean & SD & Difference \\
\hline Post test & 20.6 & 5.91 & 28.1 & 3.87 & 7.5 \\
\hline I Follow up & 17.1 & 3.38 & 26 & 3.23 & 8.9 \\
\hline II follow up & 16.8 & 4.63 & 23.6 & 3.5 & 6.8 \\
\hline
\end{tabular}

Table 4 : shows the Mean, SD and mean difference of the Depression in the Interventional and control group patients. $\mathrm{N}=20$.

\begin{tabular}{|l|c|c|c|c|c|}
\hline \multirow{2}{*}{$\begin{array}{l}\text { Data colle- } \\
\text { ction Point }\end{array}$} & \multicolumn{2}{|c|}{ Interventional } & \multicolumn{2}{c|}{ Control } & Mean \\
\cline { 2 - 6 } & Mean & SD & M ean & SD & Difference \\
\hline Post test & 17.2 & 7.036 & 21.4 & 4.248 & 4.2 \\
\hline I follow up & 14.4 & 6.132 & 20.3 & 3.529 & 5.9 \\
\hline II Follow up & 13.1 & 5.486 & 18.1 & 4.095 & 5 \\
\hline
\end{tabular}

Table 5. Two way analysis of variance on quality of life, Distress and depression between the group and within group. $\mathrm{N}=20$

\begin{tabular}{|l|c|c|}
\hline Variables & F value & P value \\
\hline Quality of life & 20.3 & $0.00 \mathrm{~S}^{* *}$ \\
\hline DistresS & 25.2 & $0.00 \mathrm{~S}^{*}$ \\
\hline Depression & 5.18 & $0.03 \mathrm{~S}$ \\
\hline
\end{tabular}

\section{$S, S^{*}, S^{* *}$ - significant $(P<0.05,0.01,0.001)$} NS- Non Significant df $=18$

\section{Results:}

Results presented asfollows

Table 1 reveals baseline mean of quality of life is 56.3 SD 6 in the interventional group and 66.2 SD 7.7 in control group .Distress mean is 28.3 SD 6.3 in the interventional group and 27.1 SD 3 in the control group. Depression mean is 22.5 SD 7.2 in the interventional group and 22 and 4.5 in the control group Independent $t$ test value obtained were $0.15 P>0.05,0.5 P>0.05,0.18 P>0.05$ for quality of life, psychological distress and depression respectively. It shows that there is no significant difference between baseline values of quality of life distress and depression between the Interventional and control group.

Table 2 shows that in the Interventional group, mean of quality of life was $56.3,65.2,67.8$ and 70.4 in the pretest, posttest, I follow up and II follow up respectively. In the control group, mean of quality of life was $56.28,53.06,54.6$ and 52.2 in the pretest, posttest, I follow up and II follow up respectively. Quality of life is significantly increased in the quality of life after the bibliotherapy in the interventional group than the control group.

Table 3 shows that , In the Interventional group, mean of psychological distress was 28.3,20.6,17.1 and 16.8 in the pretest, posttest , I follow up and II follow up respectively. In the control group, mean of psychological distress was 27.1, 28.1, 26 and 23.6 in the pretest, posttest, I follow up and II follow up respectively. After the bibliotherapy there is a significant decrease in the psychological distress in the interventional group than the control group.

Table 4 shows that in the Interventional group, mean of depression was 22.5, 17.2, 14.4 and 13.1 in the pretest, posttest, I follow up and II follow up respectively. In the control group ,mean of depression was 22,21.4,20.3 and 18.1 in the pretest, posttest, I follow up and II follow up respectively .After the bibliotherapy a significant decrease in depression in the interventional group in the I follow up and II follow up than the control group. 
Table 5 shows the two way analysis (ANOVA) of variance of quality of life, psychological distress and depression in various points of time between the Interventional and control group. $F$ value obtained between groups indicated that statistically, there is significant difference between the intervention and control group. Interventional group, quality of life is significantly increased than the control group. Psychological distress and Depression significantly decreased in the intervention group than the control group. Bibliotherapy was effective improving the quality of life and decreasing the distress and depression.

\section{Discussion}

Pilot trail findings were discussed in to two aspects

\section{a) Baseline level of quality of life, distress and depression}

Baseline level of quality of life, distress and depression implies that there is no significant difference in the level of quality of life, distress and depression in both interventional and control group ( $p>0.05$ ). Findings show that there is mean of the quality of life (56.3), distress (28.3) and depression (22.5) were produced moderate impact among the patient suffering with chronic leg and footulcer.

Above findings was supported by the study conducted Jones JE, Robinson J, Barr W, Carlisle C in UK on Impact of exudates and odour from chronic venous legulceration ${ }^{9}$.

\section{b) Effectiveness of Bibliotherapy}

Two way analysis of variance proves that bibliotherapy

\section{References:}

1. Vowden K, Vowden P, Posnett J. The resource costs of wound care in Bradford and Airedale primary care trust in the UK. Journal of Wound Care. 2009;18(3):93-98.

2. Gupta N, Gupta SK, Shukla VK, Singh SP.An Indian community-based epidemiological study of wounds. Journal of Wound Care . 2004 Sep;13(8):323-5

3. Dr.T Prabakhar clinical study of the ulcer of the leg 2006 dissertation submitted to RGUHS.

4. K. Solowiej, BSc (Hons), V. Mason, PhD and D. Upton, PhD, FBPsS psychological stress and pain in wound care part 2 Review of pain and assessment of tools. The journal of wound care vol 19, no 3, March 2010; page no:109-115.

5. A world federation of mental health report .Nightingale nursing Times.vol6,no.7.october 2010; page no:3-4.

6. Dr Ganesh Kumar, Physical illness may affect mental health.TNN, Oct 11, 2010, 05.35am IST.www.google.com highly significant in increasing quality of life ( $F=$ $20.3, P \varangle 0.001$ ) ,decreasing the psychological distress $(F=25.2, P<0.01)$ and decreasing depression $(F=5.18$ $, \mathrm{P} \varangle 0.05)$.Comparatively psychological distress, quality of life were shows highly significant difference in the interventional group than the depression. Bibliotherapy to the mild and moderate depression is less effective in the course of administration than the psychological distress.

Effectiveness of bibliotherapy was supported by the study of Songprakun W and McCann TV. On Evaluation of a bibliotherapy manual for reducing psychological distress in people with depression: a randomized controlled trial in Thailand ${ }^{10}$.

\section{Conclusion}

Chronic leg and foot ulcers are disabling and constitute a significant burden on clients and the health-care system and it have a negative psychological impact on clients and families. Bibliotherapy is helps the patient to cope with the illness, reduce the psychological impact. Pilot trail proves that bibliotherapy is significantly effective in improving the quality of life and reducing distress and depression in chronic leg and foot ulcer. Pilot trail gave root to conduct main study for the researcher.

\section{Acknowledgement :}

Our heartfelt thanks to the ethical and research committee of the Nitte university and K.S Hedge medical college hospital. Our special thanks to the valuators of the book, Traslators and Language valuators of the Instruments

7. Kevin Y Woo .wound related pain: anxiety stress and wound healing a clinical review. Wounds UK, 2010, Vol6, No 4 www.google.com

8. Pehrsson, D. E., \& McMillen, P. Bibliotherapy: Overview and implications for counselors (ACAPCD-02). Alexandria, VA: American Counseling Association;2007.

9. Naylor EV et al Bibliotherapy as a treatment for depression in primary care. Journal of Clinical Psychology in Medical Settings. 2010 September;17(3):258-71.

10. Jones JE, Robinson J, Barr W, Carlisle C. Impact of exudates and odour from chronic venous leg ulceration. Nursing Standard. 2008 Jul 1622;22(45):53-4, 56, 58 .

11. Songprakun W and M cCann TV. Evaluation of a bibliotherapy manual for reducing psychological distress in people with depression: a randomized controlled trial. Journal of Advanced Nursing. 2012 Dec; 68(12):2674-84 